\title{
C-N triple bond cleavage via trans-membrane hydrogenation
}

Yuxuan Zhang ${ }^{1}$ and Nikolay Kornienko ${ }^{1 *}$

${ }^{1}$ Department of Chemistry, Université de Montréal, 1375 Avenue Thérèse-Lavoie-Roux, Montréal, QC H2V 0B3, Canada.

*E-mail: nikolay.kornienko@umontreal.ca

\begin{abstract}
:
The renewable energy-driven valorization of excess feedstocks into commodity chemicals and societally useful products constitutes a longstanding push in energy and sustainability research. To this end, this work pushes to expand the scope of green electrosynthesis by innovating a new approach to convert acetonitrile, industrially generated in excess and burned off, to in-demand ammonia and acetaldehyde products. Success here was enabled through the use of a Pd-membrane based reactor which abstracted hydrogen atoms from water, which subsequently diffused through to a separate organic compartment in which they carried out the hydrogenation reaction. In this geometry, the reaction proceeded at $5.2 \mathrm{~mA} / \mathrm{cm}^{2}$ partial current density and $60 \%$ Faradaic efficiency towards ammonia generation. Further, the transmembrane hydrogenation approach gave rise to an onset potential of $0.2 \mathrm{~V}_{\mathrm{Ag} / \mathrm{AgCl}}$, surpassing previous state-of-the-art systems by $0.7 \mathrm{~V}$. A customized infrared spectroelectrochemcal setup was built up to probe the mechanism of the reaction, which was shown to proceed through an imine hydrolysis like pathway, with the hydrogenation of the $\mathrm{NH}_{\mathrm{x}}$ species that remained being the rate-limiting steps in the process. This work establishes a new route in electrochemical nitrile hydrogenation and general opens up promising avenues in green electrosynthesis.
\end{abstract}




\section{Introduction:}

The push for global sustainability is ultimately linked to the electrification of the chemical industry as it shifts away from fossil-fuel consuming thermochemical routes ${ }^{1-3}$. There is current a strong emphasis placed on water electrolysis and $\mathrm{CO}_{2}$ reduction, and as a direct result from these efforts these technologies are maturing to economic competitiveness ${ }^{4-7}$. Apart from this, electrochemical routes must also be developed to take advantage of abundant feedstocks, including methane ${ }^{8}$, biomass platforms ${ }^{9,10}$, and excess organics like acetonitrile, which is the focus of this work. Acetonitrile is typically generated as a by-product in acrylonitrile production (produced at a scale of 5 million tons per year) and most of it is burned afterwards, generating $\mathrm{NO}_{\mathrm{x}}$ species in the process ${ }^{11}$. Its uses are primarily as an organic solvent and building block in organic synthesis, but its production far outweighs its demand ( 10-20 thousand tons per year). Against this backdrop, the development of renewable energy-powered electrocatalytic routes to convert acetonitrile into societally useful chemicals stands to make a substantial impact in the transition to sustainable society.

There is a substantial body of literature that deals with conversion of acetonitrile to amines through thermal catalysis with $\mathrm{H}_{2}{ }^{12-16}$, while electrochemical routes which derive hydrogen directly from water and are thus more sustainable are not yet as prominent. Recently, $\mathrm{Cu}$ has been shown to be effective in generating ethylamine as a product in alkaline ${ }^{17}$ or neutra ${ }^{18}$ electrolytes. Earlier works detected ammonia and ethane from acetonitrile reduction on $\mathrm{Pt}$ in acidic electrolytes ${ }^{19,20}$ A significant challenge in this direction is minimizing the competing hydrogen evolution reaction (HER) and completely hydrogenating acetonitrile and cleaving the $\mathrm{C} \equiv \mathrm{N}$ bond.

In this work, we pursued a strategy of directly hydrogenating acetonitrile (Fig. 1a) under mild conditions with water being the hydrogen source instead of $\mathrm{H}_{2}$ as it often sourced from methane ${ }^{21}$. Specifically, we took the approach of utilizing a Pd-membrane reactor, inspired by the capacity of Pd to abstract hydrogen from water and use it to hydrogenate organic species ${ }^{22,23}$, and thus enable the hydrogenation to be carried out in a predominantly organic environment. This type of reactor geometry was adapted as it further enables the hydrogenation of reactants insoluble or poorly soluble in water (e.g. $\left.\mathrm{N}_{2}\right)$ to be pursued in follow up works. In our system, protons from acidic electrolytes were reduced to hydrogen species on the surface of $\mathrm{Pd}$, and the hydrogen atoms migrated through the $\mathrm{Pd}$ to reach the acetonitrile solution, at which point they subsequently hydrogenated acetonitrile to terminate at ammonia and acetaldehyde products in a newly discovered reaction pathway (Fig. 1b). As such, we have discovered a green route to the co-generation of $\mathrm{NH}_{3}$, widely used a fertilizer and currently produced via the Haber Bosch process, and acetaldehyde, currently produced at a million ton scale through the high temperature/pressure Wacker process ${ }^{24,25}$, and an important precursor for the production of many commodity chemicals. Further, as the onset potential was determined by that of the Pd hydrogenation, we have demonstrated an improvement of $\sim 0.7 \mathrm{~V}$ over the previous state-of-the-art systems utilizing a conventional electrochemical approach. ${ }^{17,18}$

An innovative infrared spectroelectrochemical setup was further utilized to probe the catalytic system as it functioned and extract out key mechanistic insights dictating the reaction process. It was determined that the reaction proceeds rapidly through a imine hydrolysis like pathway and the hydrogenation of the latent $\mathrm{NH}_{\mathrm{x}}$ species on the Pd surface is the slowest step in the reaction cycle. Overall, this work opens up new avenues in electrosynthesis, heterogeneous catalysis and spectroscopy that can be translated to a plethora of future endeavors within the research community. 

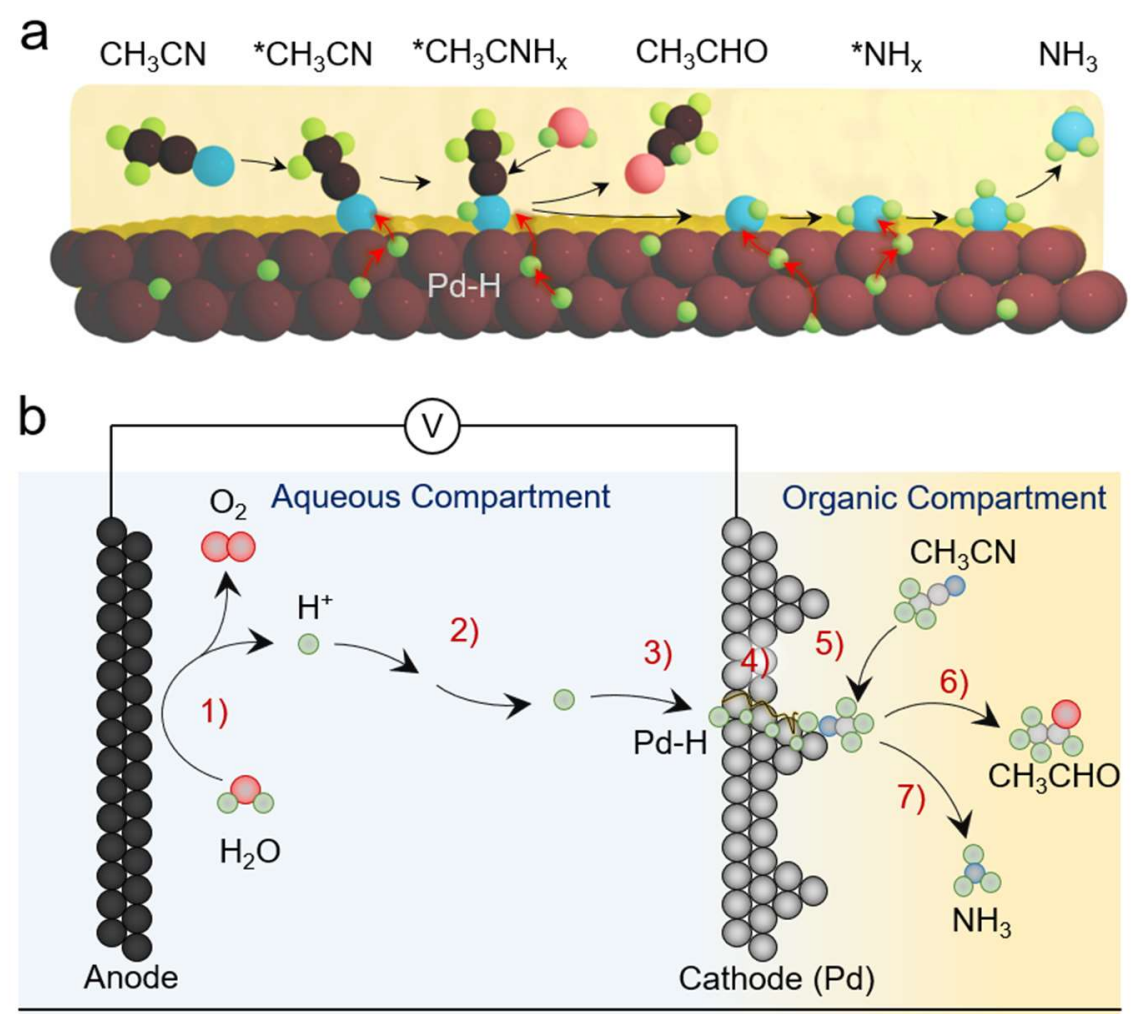
1) Water oxidation
5) Acetonitrile adsorption, hydrogenation
2) Proton diffusion
6) Acetaldehyde desorption
3) Proton reduction
7) Ammonia desorption
4) Hydrogen diffusion

Figure 1: The approached used in this work hydrogenates acetonitrile on the surface of Pd (c) to co-generate $\mathrm{NH}_{3}$ and acetaldehyde (a). Hydrogen atoms are source entirely from water and the Pd serves as a hydrogenselective membrane (b).

\section{Results and Discussion:}

The setup for our reactor closely mirrored those previously utilized in Pd-membrane hydrogenation studies $^{22}$. A commercially purchased $25 \mu \mathrm{m}$ Pd foil was used as the membrane. To increase its surface area and therefore the density of catalytic sites, Pd was further electrodeposited on the side of the foil to be eventually in contact with the acetonitrile solution, resulting in a spike-like surface (Fig. $2 \mathrm{a}$, b). In our electrochemical reactor (Fig. S1) with $\mathrm{H}_{2} \mathrm{SO}_{4}$ on one side of the $\mathrm{Pd}$ and air on the other $\left(\mathrm{H}_{2} \mathrm{SO}_{4}|\mathrm{Pd}|\right.$ air), a cyclic voltammogram shows the hydrogenation of the $\mathrm{Pd}$ and hydrogen evolution at negative potentials and a large dehydrogenation peak upon the positive sweep (Fig. 2c). When acetonitrile was on the other side instead of air $\left(\mathrm{H}_{2} \mathrm{SO}_{4}|\mathrm{Pd}| \mathrm{CH}_{3} \mathrm{CN}\right)$, the catalytic current diminished and the magnitude dehydrogenation peak also decreased. We took this to indicate that hydrogen species are being utilized for chemical reactions on the acetonitrile side of the reactor and are thus less abundant within the Pd upon the 
reverse sweep. The decrease in catalytic current likely stems in the minimization of the hydrogen evolution reaction on the aqueous side.

The NMR spectra of the solution after extended electrolysis revealed that ammonia and acetaldehyde were the two main liquid phase products present (Fig. 2d). We tracked the partial current density of $\mathrm{NH}_{3}$ generation (present as $\mathrm{NH}_{4}{ }^{+}$in acidic solutions) and saw that the production rate peaked at $-0.6 \mathrm{~V}_{\mathrm{Ag} / \mathrm{AgCl}}$. However, products can be detected as positive as $0.2 \mathrm{~V}_{\mathrm{Ag} / \mathrm{AgCl}}$, where the there is still minimal Pd hydrogenation occurring (Fig. S3). This is a remarkable improvement as recent screening of various metallic catalysts indicated that their onset of catalytic activity for acetonitrile hydrogenation is $\sim 0.7 \mathrm{~V}$ more negative than this ${ }^{17,18}$. We noted that if instead of using 'wet' acetonitrile with $60 \mathrm{mM} \mathrm{H}_{2} \mathrm{O}$ present we added in $0.2 \%(\mathrm{~V}: \mathrm{V}) 0.5 \mathrm{M} \mathrm{H}_{2} \mathrm{SO}_{4}$, our partial current density more than doubled. A similar effect was noted for the Faradaic efficiency (FE), which surpassed $60 \%$ at substantial reaction rates (Fig. 2f). The observation of acid-enhanced catalysis fueled our speculation that the reaction features a step similar to what has been observed in acid-catalyzed imine hydrolysis ${ }^{26,27}$ to yield ammonia and acetaldehyde, going through a surface-bound acetonitrile-derived intermediate. The remainder of the current likely stems from primarily hydrogen evolution and minor side reactions and generation of formate (occasional peak observed at 8.3 ppm in the NMR spectra). Further, the system exhibited stability for more than $80 \mathrm{hrs}$ and electron microscopic evaluation of the Pd surface did not reveal any significant changes in the appearance of the Pd (Fig. S5-7). 
a

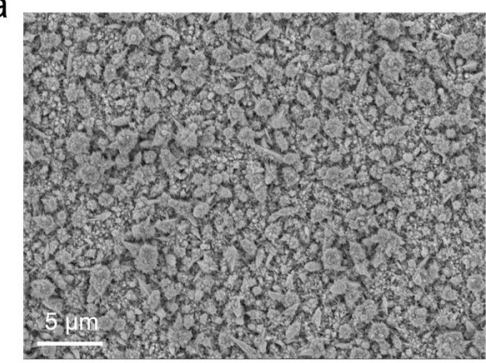

C

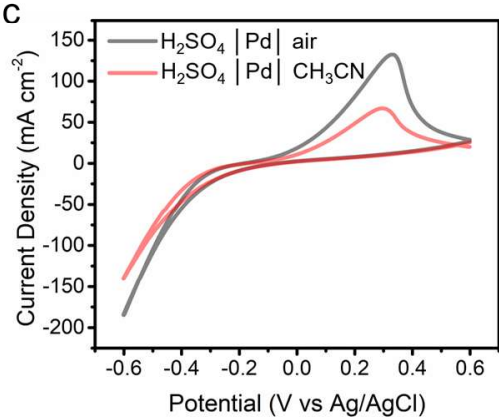

e

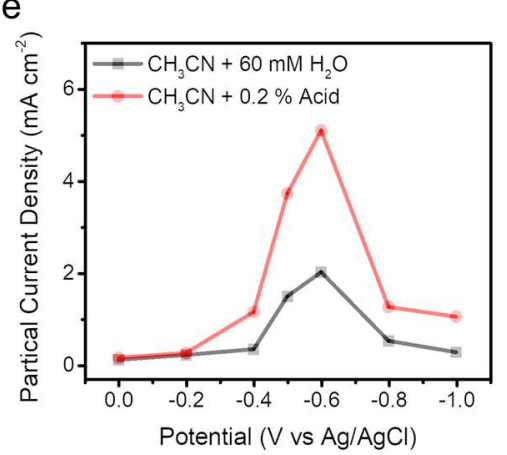

b

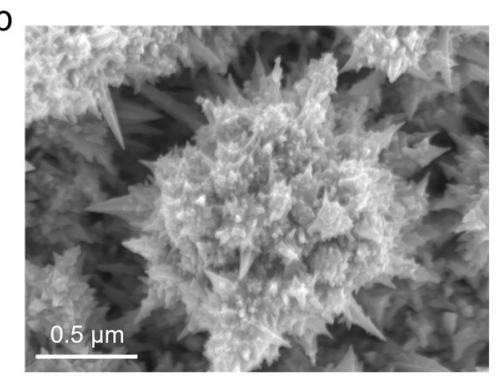

d

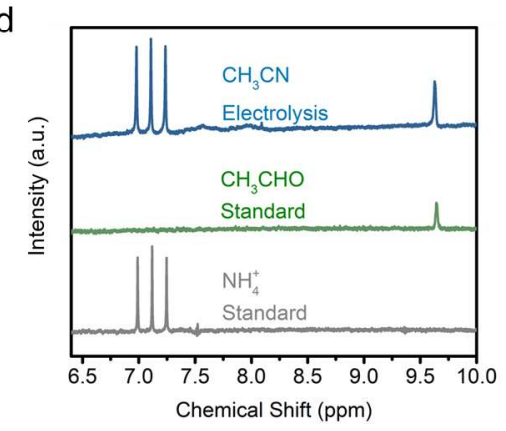

$\mathrm{f}$

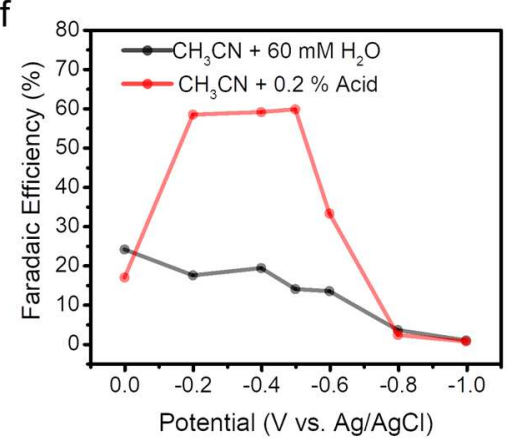

Figure 2: Scanning electron micrographs of the rough Pd surface $(a, b)$. CVs illustrate the Pd hydrogenation and dehydrogenation processes (c) with the NMR results pointing to the co-generation of ammonia and acetaldehyde (d). The partial current density (e) and Faradaic efficiency (f) are both improved when $0.2 \%$ sulfuric acid is added to the organic compartment. 
To obtain a mechanistic handle on the reaction, we moved to spectroscopically investigate the process. To realize this, we constructed a customized cell in which a thin acetonitrile layer was sandwiched between a diamond coated ZnSe prism used for attenuated total reflection (ATR) measurements and the Pd foil (Fig. 3a). Thus, this would enable the probing of solubilized species in the acetonitrile and surface catalysis on the Pd. On the other size of the Pd was the aqueous compartment with the reference and counter electrodes. We note that to the best of our knowledge, this is the first time such a measurement was carried out on a Pd-membrane hydrogenation system and thus stands to open many new opportunities in the field.

We first measured the spectrum of the system at open circuit (between 0.4 and $0.5 \mathrm{~V} \mathrm{Ag} / \mathrm{AgCl}$ ) and used this as a reference against which spectral changes were recorded either as a function of potential or time. Upon moving the potential more negative than open circuit, positive bands began to appear, with the strongest located at $\sim 2900,1725,1283,1128$, and $1074 \mathrm{~cm}^{-1}$ (Fig. 3b). The bands at 2900 and $1725 \mathrm{~cm}^{-1}$ match almost perfectly the bands corresponding to the $\mathrm{C}-\mathrm{H}$ and $\mathrm{C}=\mathrm{O}$ stretches of acetaldehyde, respectively (Fig. S8). A growing negative band at $2252 \mathrm{~cm}^{-1}$ matched well with the band corresponding to the $\mathrm{C} \equiv \mathrm{N}$ bond stretch for acetonitrile and indicated its depletion. The species at 1283, 1128, and $1074 \mathrm{~cm}^{-1}$ were deemed to be related to hydrogenated species as those bands exhibited the expected red-shifts of $30-50 \mathrm{~cm}^{-}$ ${ }^{1}$ if $\mathrm{D}_{2} \mathrm{O} / \mathrm{D}_{2} \mathrm{SO}_{4}$ was used in the aqueous compartment instead (Fig. $3 \mathrm{c}$ ). Bands in this spectral region were previously noted in studies of $\mathrm{N}_{2}$ or $\mathrm{NO}_{3}$ reduction to ammonia ${ }^{28-30}$ and thus, the assignment of these bands in our spectra to $\mathrm{NH}_{\mathrm{x}}$ species is therefore reasonable.

To deepen our insights into the chemistry at play in our Pd-membrane hydrogenation process, we probed the system as a function of time immediately after jumping from open circuit to $-0.6 \mathrm{~V}_{\mathrm{Ag} / \mathrm{AgCl}}$ (Fig. $3 \mathrm{~d})$. We tracked the integrated intensity of the main bands as a function of time and individually normalized them to their intensity at the end of the measurement (at $22 \mathrm{~min}$ ) for ease of comparison Fig. 3e). The intensities plateaued at 10-12 minutes, so the figure is zoomed in on this time period. Immediately evident was that the acetaldehyde bands (2900 and $1725 \mathrm{~cm}^{-1}$ ) and the $1283 \mathrm{~cm}^{-1}$ band rose with the same time constant. Thus, we attribute the 1283 band as a first hydrogenated species $\left(* \mathrm{NH}\right.$ or $\left.* \mathrm{NH}_{2}\right)$ that is remaining on the Pd surface after the imine hydrolysis step to generate acetaldehyde. In contrast, the bands at 1128 and $1075 \mathrm{~cm}^{-1}$ took longer to reach their maximum intensity and are thus attributed to a further hydrogenated species that remains on the $\mathrm{Pd}$ after acetaldehyde formation (either $* \mathrm{NH}_{2}$ or $* \mathrm{NH}_{3}$ ) in this case. The ratios between the 1128 and $1075 \mathrm{~cm}^{-1}$ bands and the 1283, 2900 and $1725 \mathrm{~cm}^{-1}$ are plotted in the inset of Fig. 3e as a complementary way to visualize the time-delay in generating this $2^{\text {nd }} * \mathrm{NH}_{\mathrm{x}}$ species. Thus, the spectroscopic data paints a picture in which the initial acetonitrile adsorption and hydrogenation, alongside of the imine hydrolysis occur rapidly and the final hydrogenation of the $* \mathrm{NH}_{\mathrm{x}}$ species is the slower of the adsorbed steps. Further, products are observed starting from $0.4 \mathrm{~V}_{\mathrm{Ag} / \mathrm{AgCl}}$, indicating that the thermodynamic onset is simply determined by the potential in which the Pd-hydrogenation commences. 
a

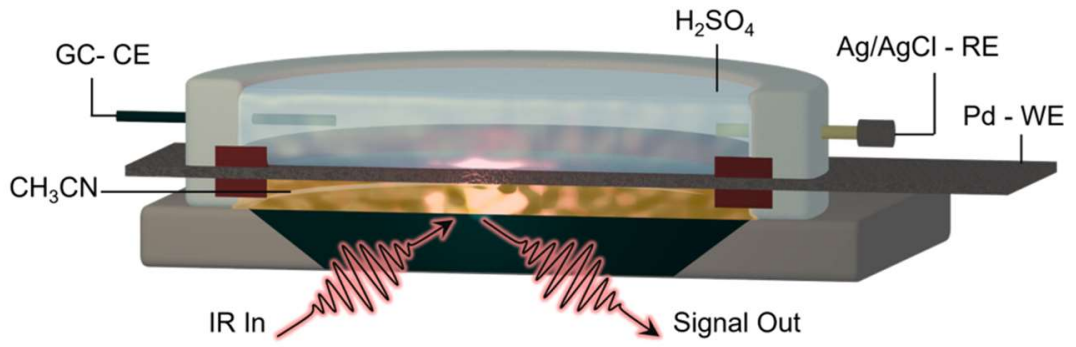

b
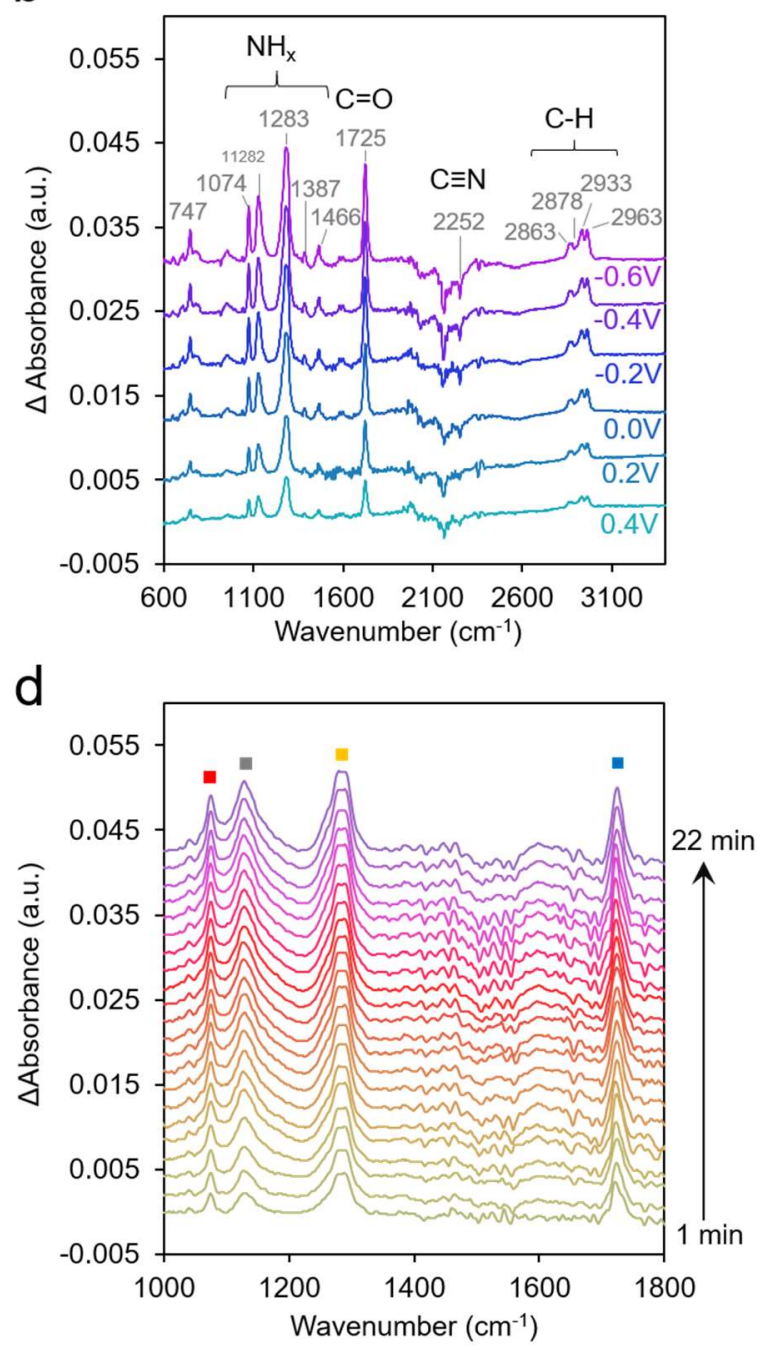

C
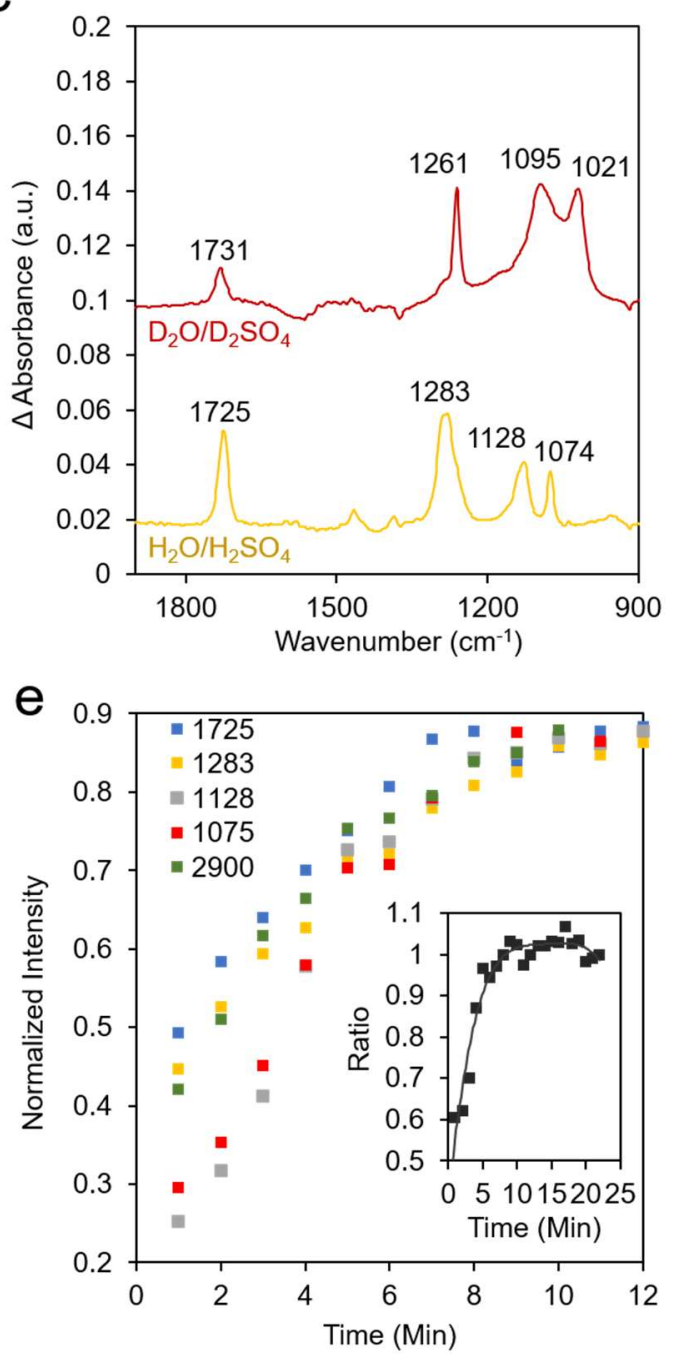

Figure 3: Spectroelectrochemical configuration employed to probe the reaction process (a). Spectra were recorded as a function of applied potential (b) and bands corresponding to hydrogenated products were identified with isotope labeling experiments (c). Time dependent spectra (d) were used to track the evolution of individual species (e). 
Through the sum of our electrochemical and spectroscopic studies, we come to a unique reaction mechanism enabling the synthesis of acetaldehyde and ammonia from acetonitrile (Fig. 4). We believe that the initial adsorption and hydrogenation occurs rapidly, as does the imine hydrolysis step as acetaldehyde is immediately visible in the infrared spectra. Instead, the downstream protonation steps take longer to carry out, judging form the slow rise in the bands corresponding to latent ${ }^{*} \mathrm{NH}_{\mathrm{x}}$ species. Following successive hydrogenation steps, the ammonia product desorbs into the solution and is eventually protonated to give rise to the ammonium signal observed in the NMR spectra.

Instead of terminating at ethylamine, the unique synthetic approach enables the complete cleavage of the $\mathrm{C} \equiv \mathrm{N}$ triple bond. Further, as the reaction onset is limited by the Pd hydrogenation potential, it is possible to carry out the reaction before the thermodynamic potential for the hydrogen evolution reaction is reached. This offers a substantial advantage over a conventional electrosynthetic scheme where, for example, onset potentials for a variety of metallic catalysts were on the order of $-0.3 \mathrm{~V}_{\mathrm{RHE}}{ }^{17,18}$, with our work offering an improvement of $0.7 \mathrm{~V}$ over this value.

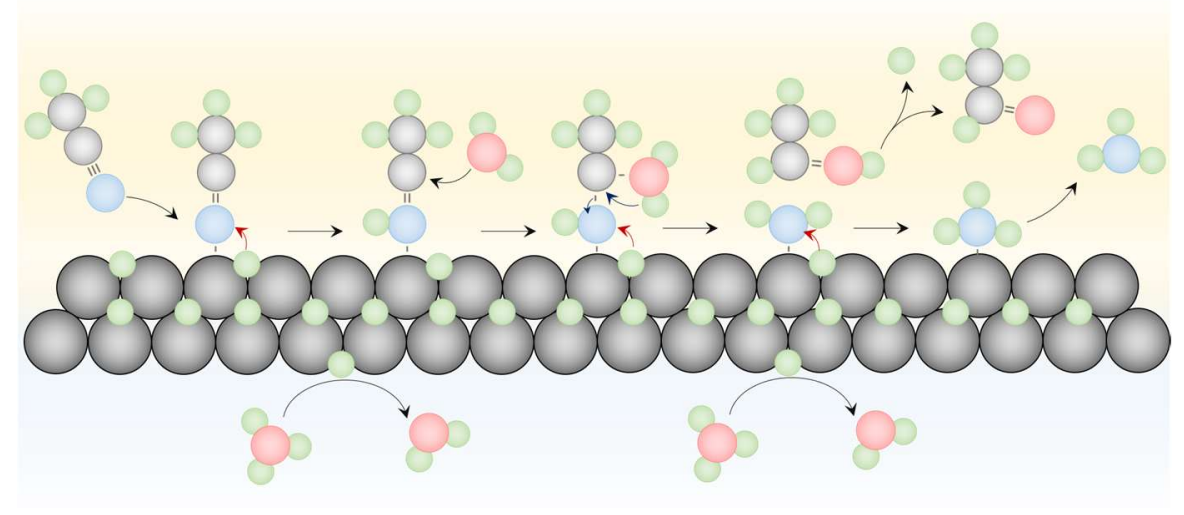

Figure 4: Proposed catalytic reaction mechanism for acetonitrile conversion into ammonia and acetaldehyde, driven by Pd-membrane hydrogenation.

\section{Concluding Remarks:}

With the system investigated through our first round of electrochemical and spectroscopic analysis, several obvious avenues come to mind that may help improve its performance. Our catalytic Pt surface was not optimized beyond making it rough through an electrodeposition approach. As different facets, active sites, defects and more and know to display varying activity in heterogeneous catalysis, it would be beneficial to quantify through a combination of synthesis, electrochemistry, theory and spectroscopy the varying activity of the possible $\mathrm{Pd}$ active sites en route to maximizing their abundance. Further, the deposition of a co-catalyst to aid in reactant adsorption and product desorption also stands to boost the system's activity. We identified the later hydrogenation stages of $\mathrm{NH}_{\mathrm{x}}$ as being limiting and a co-catalyst may certainly help accelerate these steps. Further, reactor engineering also stands to improve the throughput of the process by facilitating mass transport and translating this over to a flow cell geometry ${ }^{31}$ could significantly boost the steady state current density. In all, this work conceptually opens many exciting routes in electrosynthesis through the discovery of complete nitrile $\mathrm{C} \equiv \mathrm{N}$ bond cleavage. We envision that this can readily be extended over to additional challenging reactions such as $\mathrm{N}_{2}$ reduction or phosphorus fixation. 


\section{Acknowledgements:}

N.K. and Y.Z acknowledge NSERC Discovery Grant RGPIN-2019-05927. In addition, the authors would like to thank Loïc P. Mangin for helpful discussion.

\section{Author Contributions:}

N.K and Y.Z both designed the project, carried out experiments, processed data, contributed intellectual insights and wrote the manuscript.

\section{Competing Interests:}

None to declare

\section{References:}

1 Chu, S. \& Majumdar, A. Opportunities and challenges for a sustainable energy future. Nature 488, 294-303 (2012).

2 Chu, S., Cui, Y. \& Liu, N. The path towards sustainable energy. Nat. Mater. 16, 16-22 (2017).

3 Davidson, D. J. Exnovating for a renewable energy transition. Nat. Energy 4, 254-256 (2019).

4 De Luna, P. et al. What would it take for renewably powered electrosynthesis to displace petrochemical processes? Science 364, eaav3506 (2019).

5 Paidar, M., Fateev, V. \& Bouzek, K. Membrane electrolysis-History, current status and perspective. Electrochim. Acta 209, 737-756 (2016).

6 Schmidt, O. et al. Future cost and performance of water electrolysis: An expert elicitation study. Int. J. Hydrogen Energy 42, 30470-30492 (2017).

7 Jouny, M., Luc, W. \& Jiao, F. General Techno-Economic Analysis of CO2 Electrolysis Systems. Ind. Eng. Chem. Res. 57, 2165-2177 (2018).

8 Richard, D., Huang, Y.-C. \& Morales-Guio, C. G. Recent Advances in the Electrochemical Production of Chemicals from Methane. Curr. Opin. Electrochem., 100793 (2021).

9 Zhang, Y., Li, J. \& Kornienko, N. Towards atomic precision in HMF and methane oxidation electrocatalysts. Chem. Commun. 57, 4230-4238 (2021).

10 Du, L. et al. Electrocatalytic valorisation of biomass derived chemicals. Catal. Sci. Tech. 8, 32163232 (2018).

11 Karsten, E., Erhard, H., Roland, R. \& Hartmut, H. (Wiley-VCH Verlag, Weinheim, 2005).

12 Gluhoi, A. C., Mărginean, P. \& Stănescu, U. Effect of supports on the activity of nickel catalysts in acetonitrile hydrogenation. Appl. Catal., A 294, 208-214 (2005).

13 Iwasa, N., Yoshikawa, M. \& Arai, M. Selective hydrogenation of acetonitrile to ethylamine using palladium-based alloy catalysts. Phys. Chem. Chem. Phys. 4, 5414-5420 (2002).

14 Verhaak, M. J. F. M., van Dillen, A. J. \& Geus, J. W. The selective hydrogenation of acetonitrile on supported nickel catalysts. Catal. Lett. 26, 37-53 (1994).

$15 \mathrm{Li}, \mathrm{H} ., \mathrm{Wu}, \mathrm{Y}$., Luo, H., Wang, M. \& Xu, Y. Liquid phase hydrogenation of acetonitrile to ethylamine over the Co • B amorphous alloy catalyst. J. Catal. 214, 15-25 (2003).

16 Braos-García, P., García-Sancho, C., Infantes-Molina, A., Rodríguez-Castellón, E. \& JiménezLópez, A. Bimetallic Ru/Ni supported catalysts for the gas phase hydrogenation of acetonitrile. Appl. Catal., A 381, 132-144 (2010).

17 Xia, R. et al. Electrochemical reduction of acetonitrile to ethylamine. Nat. Commun. 12, 1949 (2021).

18 Zhang, D. et al. Highly efficient electrochemical hydrogenation of acetonitrile to ethylamine for primary amine synthesis and promising hydrogen storage. Chem Catal. (2021). 
19 Szklarczyk, M. \& Sobkowski, J. The behaviour of high polar organic solvents at platinum electrode - II. Adsorption and electrode reactions of acetonitrile. Electrochim. Acta 25, 15971601 (1980).

20 Wasmus, S. \& Vielstich, W. Electro-oxidation and electroreduction of acetonitrile in aqueous acid solution: A DEMS study. J. Electroanal. Chem. 345, 323-335 (1993).

21 Iulianelli, A., Liguori, S., Wilcox, J. \& Basile, A. Advances on methane steam reforming to produce hydrogen through membrane reactors technology: A review. Catal. Rev. 58, 1-35 (2016).

22 Sherbo, R. S., Delima, R. S., Chiykowski, V. A., MacLeod, B. P. \& Berlinguette, C. P. Complete electron economy by pairing electrolysis with hydrogenation. Nat. Catal. 1, 501-507 (2018).

23 Sherbo, R. S., Kurimoto, A., Brown, C. M. \& Berlinguette, C. P. Efficient Electrocatalytic Hydrogenation with a Palladium Membrane Reactor. J. Am. Chem. Soc. 141, 7815-7821 (2019).

24 Smidt, J. et al. Katalytische umsetzungen von olefinen an platinmetall-verbindungen das consortium-verfahren zur herstellung von acetaldehyd. Angew. Chem. 71, 176-182 (1959).

25 Eckert, M., Fleischmann, G., Jira, R., Bolt, H. M. \& Golka, K. Acetaldehyde. 7 edn, (2006).

26 Testa, A. C. \& Reinmuth, W. H. Chronopotentiometry with Current Reversal. Application to pBenzoquinone Imine Hydrolysis. Anal. Chem. 32, 1512-1514 (1960).

27 Layer, R. W. The Chemistry of Imines. Chem. Rev. 63, 489-510 (1963).

28 Wang, M. et al. Salting-out effect promoting highly efficient ambient ammonia synthesis. Nat. Commun. 12, 3198 (2021).

29 Yao, Y., Zhu, S., Wang, H., Li, H. \& Shao, M. A Spectroscopic Study on the Nitrogen Electrochemical Reduction Reaction on Gold and Platinum Surfaces. J. Am. Chem. Soc. 140, 1496-1501 (2018).

30 Yao, Y., Zhu, S., Wang, H., Li, H. \& Shao, M. A Spectroscopic Study of Electrochemical Nitrogen and Nitrate Reduction on Rhodium Surfaces. 59, 10479-10483 (2020).

31 Jansonius, R. P. et al. Hydrogenation without H2 Using a Palladium Membrane Flow Cell. Cell Rep. Phys. Sci. 1, 100105 (2020). 
Supplementary Information for:

\section{$\mathrm{C}-\mathrm{N}$ triple bond cleavage via trans-membrane hydrogenation}

Yuxuan Zhang ${ }^{1}$ and Nikolay Kornienko ${ }^{1 *}$

${ }^{1}$ Department of Chemistry, Université de Montréal, 1375 Avenue Thérèse-Lavoie-Roux, Montréal, QC H2V 0B3, Canada.

*E-mail: nikolay.kornienko@umontreal.ca

\section{Experimental Section:}

\subsection{Chemicals:}

Hydrochloric acid $0.5 \mathrm{~N}(\mathrm{HCl})$, Sulfuric acid $1.0 \mathrm{~N}\left(\mathrm{H}_{2} \mathrm{SO}_{4}\right)$ were obtained from Anachemia company. Palladium foil (Pd, $0.025 \mathrm{~mm}$ thick, 99.9\%), Acetonitrile (99.95+\%), 2 propanol were purchased from Fisher Scientific company. Palladium Chloride $\left(\mathrm{PdCl}_{2}, 99.9 \%\right)$ was purchased from VWR international company. Sulfuric acid- $d_{2}$ solution (96-98 wt. \% in D2O, 99.5 atom \%D), Dimethyl sulfoxide- $d_{6}$ (99.9 atom $\%$ D) was get from Sigma-Aldrich Company. Ammonium Chloride $\left(\mathrm{NH}_{4} \mathrm{Cl}, 98+\%\right)$, Iron chloride hexahydrate $\left(\mathrm{FeCl}_{3} \cdot 6 \mathrm{H}_{2} \mathrm{O}, 97 \%\right)$ were purchased from Alfa Aesar company.

\subsection{Catalyst Preparation and Characterization:}

The palladium foil was prepared by an electrodeposition method. The palladium foil substrate was clamped into the middle compartment of the $\mathrm{H}$-cell as the working electrode. $\mathrm{A} 15.9 \mathrm{mM} \mathrm{PdCl}$ electrolyte in $0.5 \mathrm{~N} \mathrm{HCl}$ was used for the electrodeposition. To roughen the Pd surface, a $-0.2 \mathrm{~V}$ versus $\mathrm{Ag} / \mathrm{AgCl}$ was applied until $13 \mathrm{C}$ of charge $\left(16.56 \mathrm{C} \mathrm{cm}^{-2}\right)$ was passed for a estimated total of $7.2 \mathrm{mg}$ of palladium on the surface.

$\mathrm{An} \mathrm{Ag} / \mathrm{AgCl}$ in $3 \mathrm{M} \mathrm{KCl}$ solution was used as the reference electrodes and a graphite rod was used as the counter electrode. The $\mathrm{Ag} / \mathrm{AgCl}$ reference was periodically checked against a master reference electrode for any potential drifts to maintain stable in alkaline electrolyte. A biologic VMP200 potentiostat and EClab software were used for electrochemical experiments. To compensate for the IR drop in the solution, the ZIR program was employed by recording the impedance between the cathode and reference electrode at open circuit at $100 \mathrm{KHz}$ frequency. A typical electrolysis experiment was 90 minutes in our work. 
The morphology and microstructure of as prepared $\mathrm{Pd}$ foil were investigated by scanning electron microscopy (SEM) and transmission electron microscopy (TEM). Both the SEM and TEM images were collected at the Centre for Characterization and Microscopy of Materials at Polytechnique Montreal. SEM images were obtained using a JEOL JSM-7600F Filed Emission SEM microscope. TEM images were conducted on JEOL JEM-2100F FEG-TEM, operated at $200 \mathrm{kV}$. For TEM characterizations, samples were prepared by carefully scratched off the electrodeposition part and disperse them onto a copper grid supporting a thin electron transparent carbon film.

\subsection{Electrochemistry Analysis and Product quantification}

Electrochemistry experiments were carried out in an H-type two-compartment glass electrochemical cell. A Pd foil was pressed between the electrochemical compartments of the cell. Each compartment contained a total of $50 \mathrm{ml}$ solution volume. The electrochemical compartments obtained $1 \mathrm{~N} \mathrm{H}_{2} \mathrm{SO}_{4}$ and the chemical compartments contained acetonitrile. Cyclic voltammetry (CV) measurements were performed with the scan rate of $20 \mathrm{mV} \mathrm{s}^{-1}$ in the $\mathrm{H}_{2} \mathrm{SO}_{4}$ solution and another compartment is filled with air or with acetonitrile. $\mathrm{An} \mathrm{Ag} / \mathrm{AgCl}$ in saturated $\mathrm{KCl}$ solution was used as the reference electrodes and a graphite rod was used as the counter electrode. In all cases, the surface area of the foil on the both the chemical and electrochemical sides was measured to be $0.785 \mathrm{~cm}^{2}$.

$60 \mathrm{mM} \mathrm{H}_{2} \mathrm{O} 2 \%$ sulfuric acid solution (1N) was dissolved in acetonitrile. Subsequently, the solution was bubbled with either $\mathrm{Ar}$ or $\mathrm{N}_{2}$ gas for 30 min to remove the possible oxygen. Chronoamperometry was conducted at different potential to electrolysis of aqueous part $\left(\mathrm{H}_{2} \mathrm{SO}_{4}\right.$ electrolyte $)$ and the organic compartment is filled with $60 \mathrm{mM} \mathrm{H}_{2} \mathrm{O}$ in acetonitrile solution. In an optimized condition, the organic compartment was filled with $0.2 \%(\mathrm{~V}: \mathrm{V}) 0.5 \mathrm{M} \mathrm{H}_{2} \mathrm{SO}_{4}$ in acetonitrile solution while the aqueous part remains $0.5 \mathrm{M} \mathrm{H}_{2} \mathrm{SO}_{4}$.

For product analysis, all reactant and products were quantified with ${ }^{1} \mathrm{H}$ NMR (Bruker AVANCE II 400 se), using D-DMSO with 2-propanol as an internal standard. For all NMR sample, 400 ul of reaction mixture, $400 \mathrm{ul}$ of $10 \mathrm{mM}$ 2-propanol dissolved in D-DMSO, and $100 \mathrm{ul}$ of $1.0 \mathrm{~N} \mathrm{H}_{2} \mathrm{SO}_{4}$ were used.

\subsection{Infrared spectroscopy:}

Infrared spectroscopy in an ATR configuration was performed with ThermoFischer Nicolet 380 FTIR-ATR system with a ZnSe ATR crystal coated with a diamond surface. For ex-situ measurements, each spectrum was recorded with an accumulation of 400 scans with a resolution of $4 \mathrm{~cm}^{-1}$.

For in situ IR spectroscopy, the experiments were executed with the use of a custom-designed spectroelectrochemical cell. The electrodeposited Pd foil was the working electrode to separate the $\mathrm{H}_{2} \mathrm{SO}_{4}$ and the acetonitrile solution. Simultaneously, $\mathrm{Cu}$ wire was used as the counter electrode and the $\mathrm{Ag} / \mathrm{AgCl}$ was used as the reference. The background spectrum was recorded the open circuit potential (between 0.4 and $0.5 \mathrm{~V}$ vs. $\mathrm{Ag} / \mathrm{AgCl}$ ) with an accumulation of 200 scans and this was then subtracted from the spectra at certain potential or time values. 


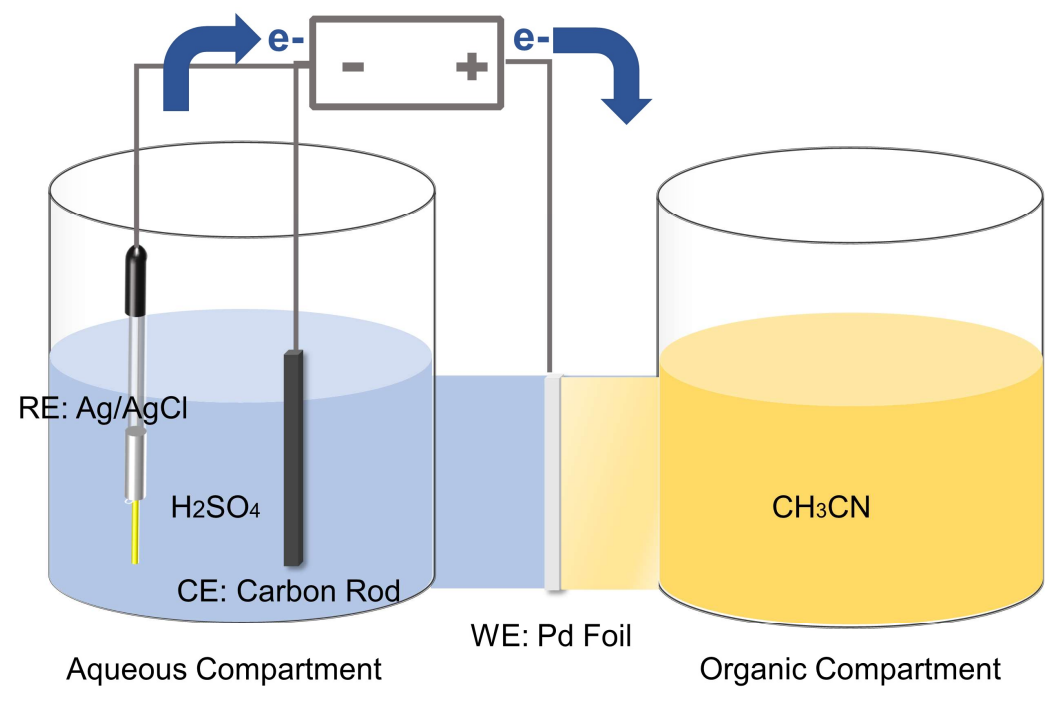

Figure S1: Simplified schematic of the electrochemical setup employed in this work

a

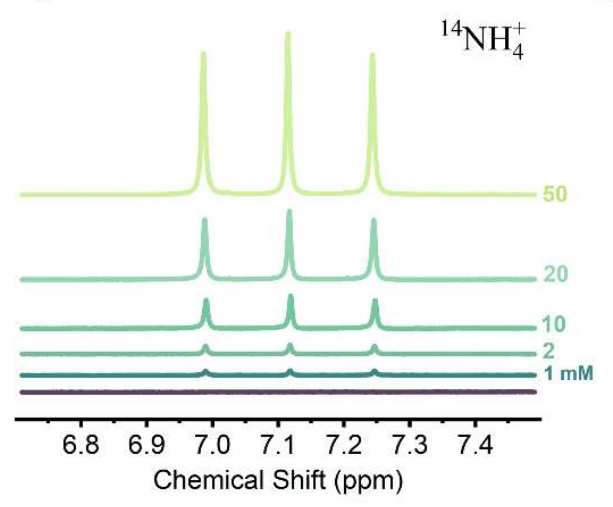

b

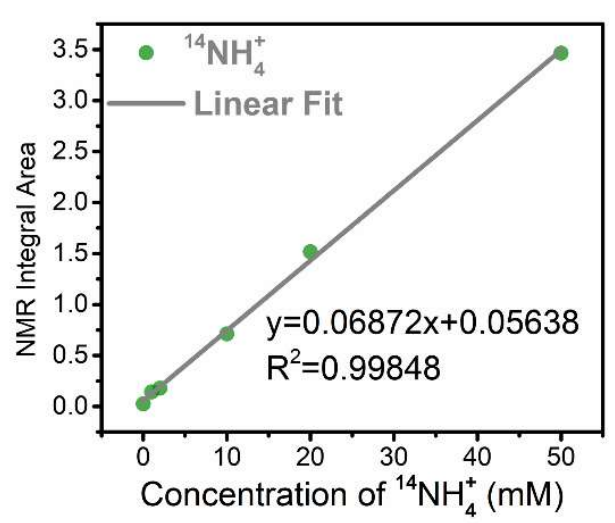

Figure S2: $\mathrm{NH}_{4}{ }^{+} \mathrm{NMR}$ spectra (a) and calibration curve (b) 


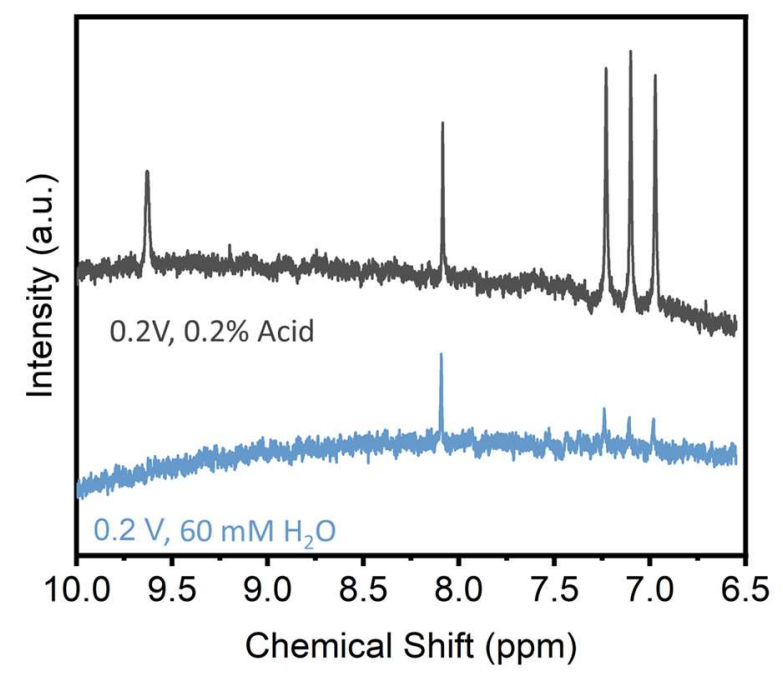

Figure S3: $\mathrm{NH}_{4}{ }^{+}$ace acetaldehyde generated form electrolysis at $0.2 \mathrm{~V}_{\mathrm{AgAgCl}}$.

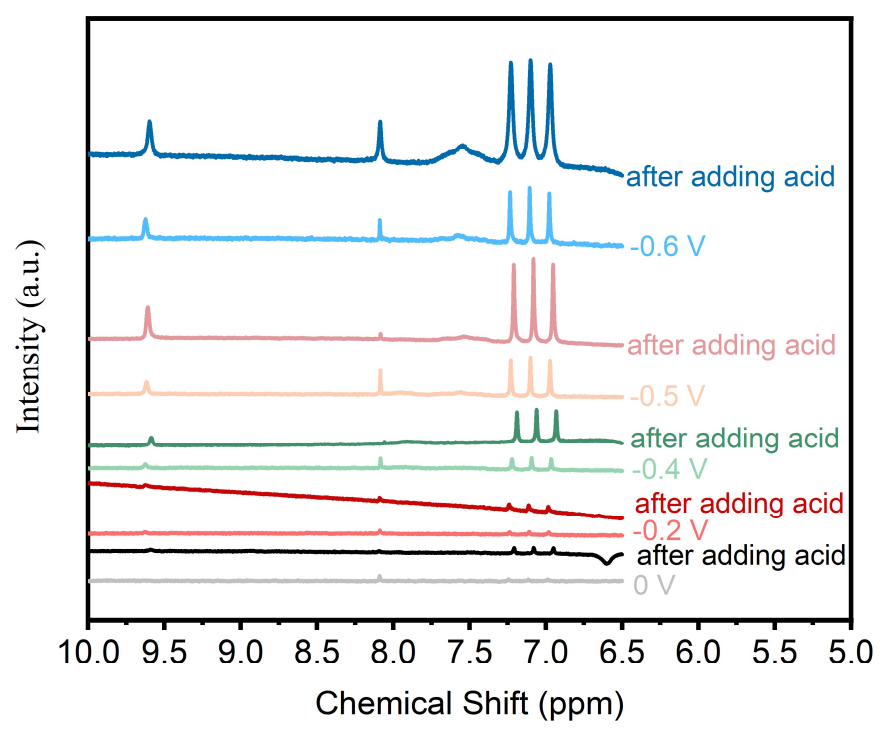

Figure S4: Representative NMR spectra of the solution after electrolysis with either $60 \mathrm{~mm} \mathrm{H}_{2} \mathrm{O}$ with $0.2 \% \mathrm{H}_{2} \mathrm{SO}_{4}$ in the solution. Potentials are referenced to $\mathrm{Ag} / \mathrm{AgCl}$ 


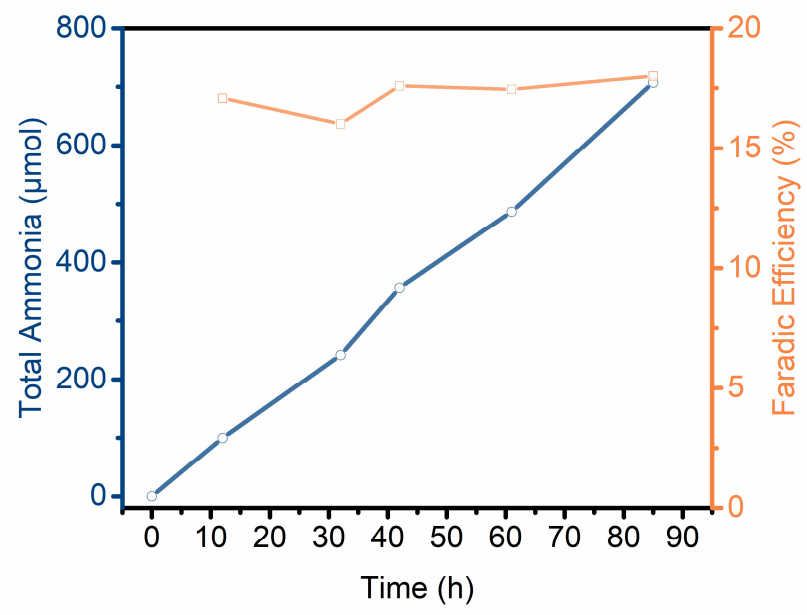

Figure S5: Demonstration of the stability of the system using $60 \mathrm{mM} \mathrm{H}_{2} \mathrm{O}$ at $-0.6 \mathrm{~V}_{\mathrm{Ag} / \mathrm{AgCl} \text {. }}$
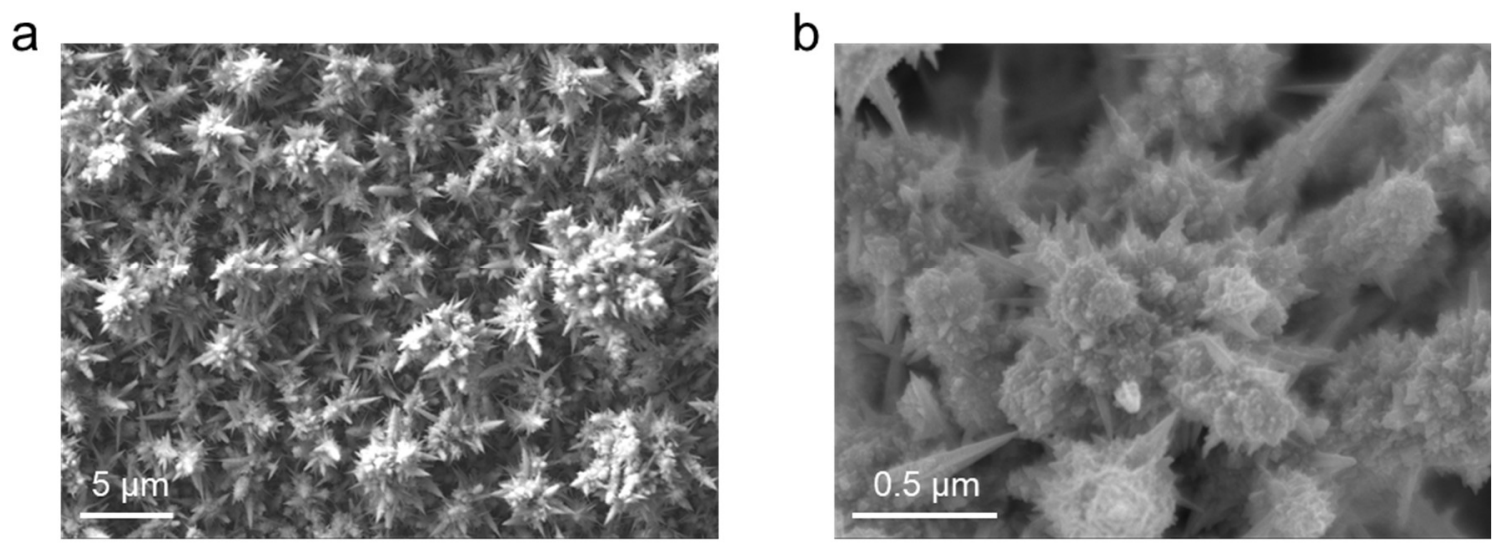

Figure S6: SEM images with low (a) and high (b) magnification of the Pd after a typical electrolysis experiment at $-0.6 \mathrm{~V}_{\mathrm{Ag} / \mathrm{AgCl} \text {. }}$ 
a

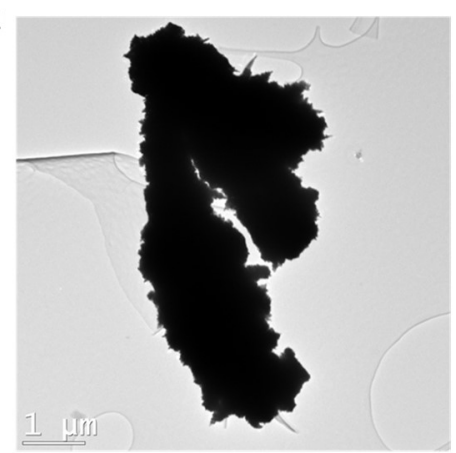

C

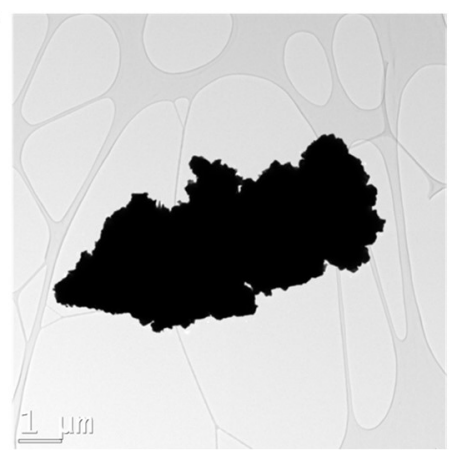

b

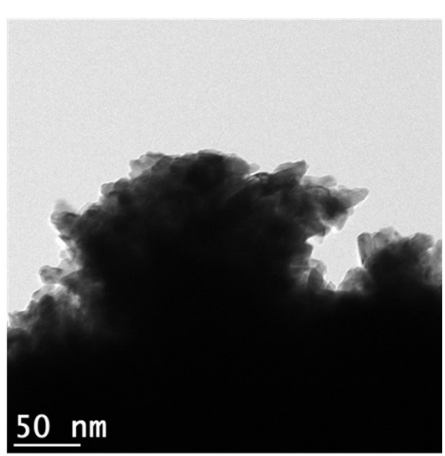

d

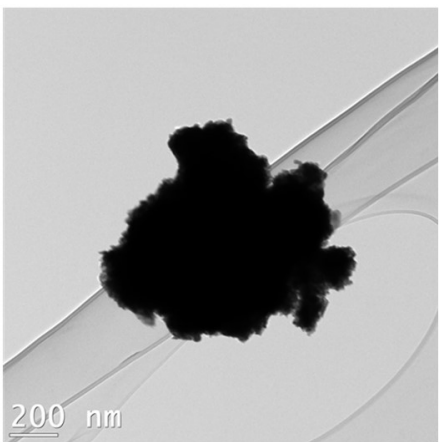

Figure S7: TEM images of the Pd (scratched off the electrode) before electrolysis $(a, b)$ and after electrolysis $(c, d)$ at $-0.6 \mathrm{~V}_{\mathrm{Ag} / \mathrm{AgCl}}$. Higher resolution imaging was not possible due to the instability of the $\mathrm{Pd}$ under high electron flux in our setup. 


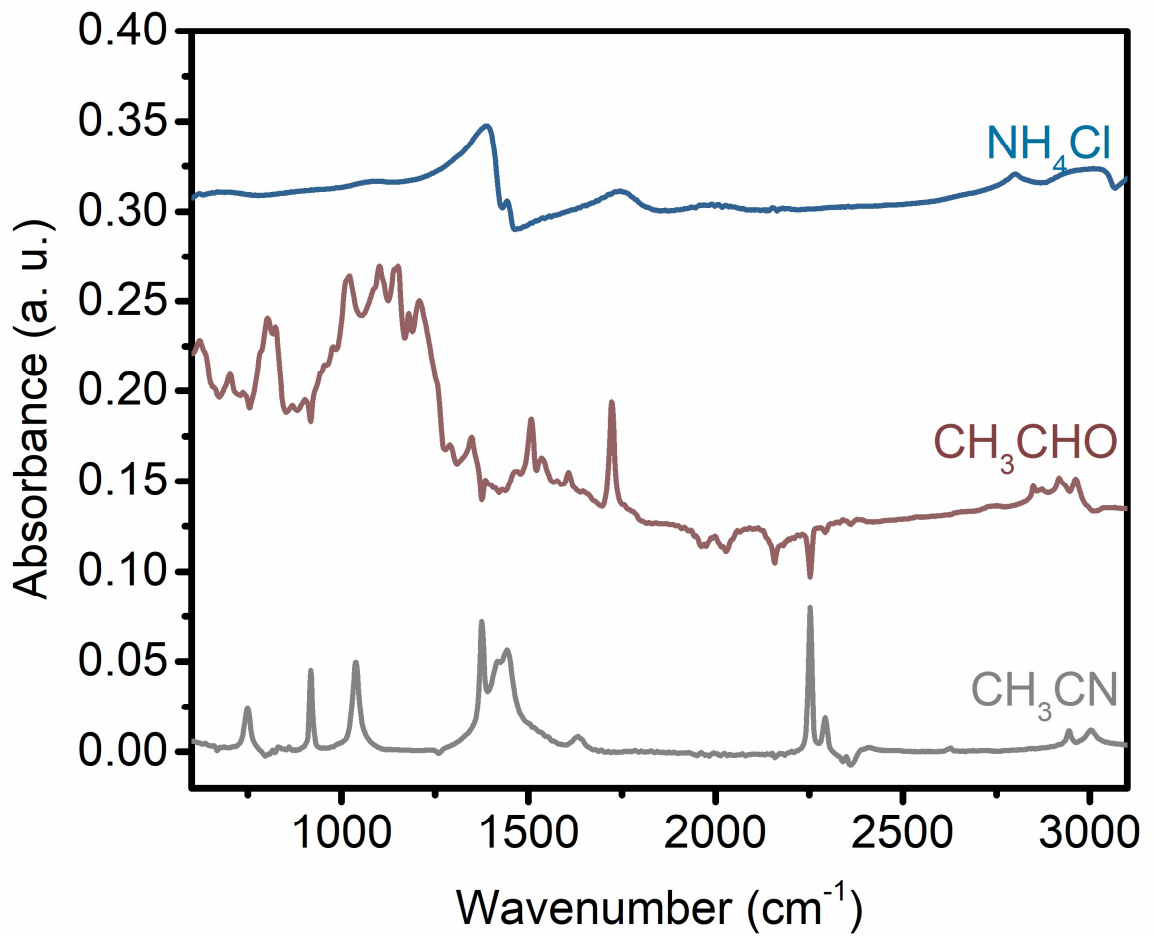

Figure S8: Infrared spectra of several reference compounds 


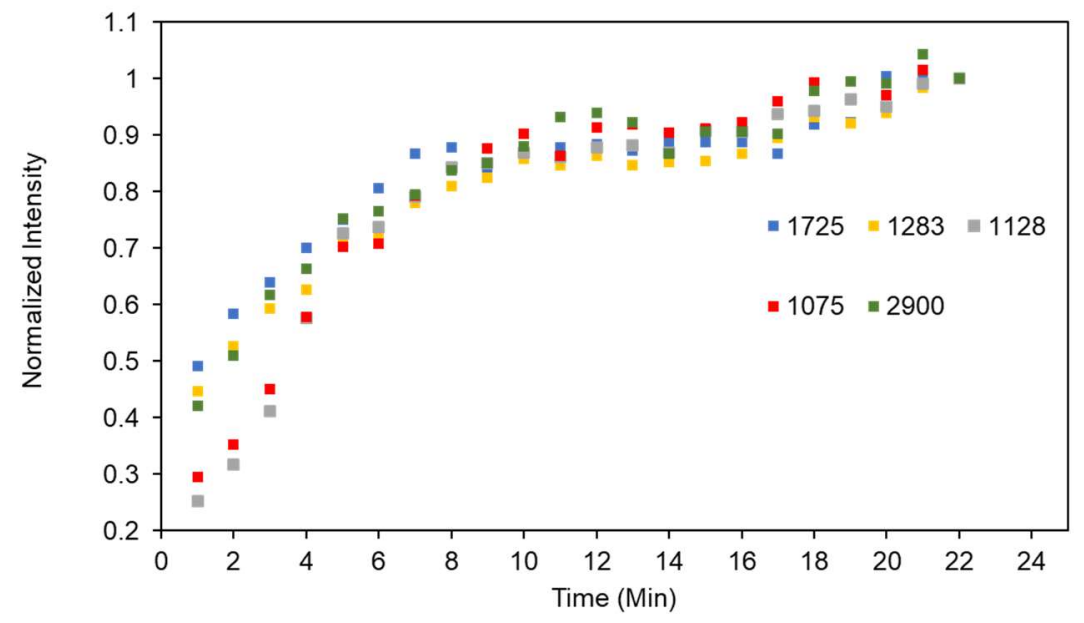

Figure S9: Time-dependent peak changes at longer timescales at $-0.6 \mathrm{~V}_{\mathrm{Ag} / \mathrm{AgCl}}$ 